\title{
EDUCAÇÃO RURAL: ações pedagógicas e infâncias
}

\author{
Josemir Almeida Barros ${ }^{1}$ \\ Nilce Vieira Campos Ferreira ${ }^{2}$
}

\begin{abstract}
RESUMO
A pesquisa versou sobre a educação rural, ações pedagógicas e infâncias, temática pertinente e pouco problematizada ao tratarmos da região Norte do país, especificamente, de Porto Velho-RO, local em que as redes de ensino de educação básica representadas por escolas estaduais e municipais possuem significativo número de estudantes pequeninos e jovens. Nesse sentido, falar de ações pedagógicas também significa melhor entender os processos pelos quais as redes de ensino responsáveis pelas escolas rurais se organizam: seja em termos de estrutura física, seja em concepções de ensino para exercer as atividades no interior das escolas rurais. A pesquisa trouxe como objetivos analisar as propostas de educação para crianças no meio rural destinadas à população carente e seus vínculos com processo de produção capitalista e pesquisar as normas que estabeleceram os modelos de escola para o meio rural. Para tanto, algumas indagações foram expostas: qual foi o lugar ocupado pela educação pública destinada às crianças moradoras do meio rural no município de Porto Velho? As políticas de organização das escolas de Porto Velho levaram em consideração os processos formativos e os contextos vivenciados por alunos e professores das escolas rurais? Quais as concepções de infâncias que circulam nas escolas rurais? Em termos metodológicos, acessamos documentos diversos no Palácio Getúlio Vargas, no Conselho Estadual de Educação e no interior de algumas escolas situadas em áreas rurais em Porto Velho. Por fim, utilizamos o software Maxada na etapa de categorização dos dados.
\end{abstract}

Palavras-chave: Ensino rural. Infância rural. Escola rural.

\section{RURAL EDUCATION: pedagogical actions and infancies}

\begin{abstract}
The research dealt with rural education, pedagogical actions and infancies, a relevant and little problematized theme when dealing with the northern region of the country, specifically, Porto Velho-RO, where primary and secondary education networks represented by state schools and municipal schools have a significant number of children and teenagers. In this sense, discussing pedagogical actions also means better understanding the processes by which the education networks responsible for rural schools are organized: either in terms of physical structure or conceptions of teaching to act within rural schools. The research aimed to analyze the education proposals for children in rural areas for the needy population and their

\footnotetext{
1 Pós-Doutor, Doutor e Mestre em Educação. Prof. da Universidade Federal de Rondônia UNIR, Rondônia, Brasil. Orcid iD: https://orcid.org/0000-0002-2687-6575. E-mail: josemirbh@gmail.com

2 Pós-Doutora, Doutora e Mestra em Educação. Professora da Universidade Federal de Mato Grosso - UFMT, Mato Grosso, Brasil. Orcid iD: https://orcid.org/0000-0002-9165-001 1. E-mail: nilcevieiraufmt@gmail.com
} 
links with the capitalist production process and to research the norms that established school models for rural areas. Therefore, some questions were raised: what was the place occupied by public education for children living in rural areas in the city of Porto Velho? Did the school organization policies in Porto Velho consider the training processes and contexts experienced by students and teachers in rural schools? What are the conceptions of infancies that circulate in rural schools? In methodological terms, we access different documents at the Getúlio Vargas Palace, at the State Education Council and in some schools located in rural areas in Porto Velho. Finally, we used the MAXQDA software in the data categorization stage.

Keywords: Rural education. Rural infancies. Rural school.

\section{EDUCACIÓN RURAL: acciones pedagógicas y niñez}

\section{RESUMEN}

La investigación abordó la educación rural, las acciones pedagógicas y la niñez, un tema relevante y poco problematizado cuando se trata de la región norte del país, específicamente, Porto Velho-RO; un lugar donde las redes de enseñanza de educación básica representadas por las escuelas del estado y de la municipalidad poseen un número significativo de estudiantes pequeños y jóvenes. En este sentido, hablar de acciones pedagógicas también significa comprender mejor los procesos mediante los cuales se organizan las redes educativas responsables por las escuelas rurales: ya sea en términos de estructura física o en concepciones de enseñanza para ejercer actividades dentro de las escuelas rurales. La investigación tuvo como objetivo analizar las propuestas educativas para niños en áreas rurales destinadas a la población necesitada y a sus vínculos con el proceso de producción capitalista para investigar las normas que establecieron modelos escolares para las áreas rurales. Por lo tanto, se plantearon algunas preguntas inciciales: ¿̇cuál ha sido el lugar ocupado por la educación pública para los niños que viven en las zonas rurales de la ciudad de Porto Velho? ¿̇as políticas de organización escolar en Porto Velho tomaron en cuenta los procesos y contextos de capacitación experimentados por estudiantes y maestros en las escuelas rurales? ¿Cuáles son las concepciones de niñez que circulan en las escuelas rurales? En términos metodológicos, accedemos a diferentes documentos en el Palacio Getúlio Vargas, en el Consejo de Educación del Estado y dentro de algunas escuelas ubicadas en áreas rurales en Porto Velho. Finalmente, utilizamos el software Maxada en la etapa de categorización de datos.

Palabras clave: Educación rural. Niñez rural. Escuela rural.

\section{INTRODUÇÃO}

Ao elegermos a educação rural na condição de objeto de investigação3, é pertinente lembrarmos o quanto essa categoria de ensino integrou uma das facetas em que a área rural só era enfatizada se os processos de produção de mercadorias fossem lucrativos. É verdade que o

\footnotetext{
3 A investigação contou com financiamento da CAPES, CNPq e FAPERO.
} 
Brasil até meados do século XX era rural, mas nem sempre os investimentos públicos financeiros eram destinados à constituição e/ou execução de políticas públicas sociais para a educação rural.

Ao enfatizarmos a categoria rural juntamente aos processos de ensino e aprendizagem, remetemo-nos ao passado para averiguar o quanto há de permanências de um tempo no outro. Não por acaso, o tempo presente é repleto de fragmentos ou memórias do passado.

Como Walter Benjamin (1994) ensinou que conhecer o passado é também uma das formas de ressignificar o presente e projetar o futuro, assim, voltar o olhar para o passado, expresso nos diversos documentos, é também desvendar indícios que permitam ressignificar a história da educação. Esta, por sua vez, é "[...] objeto de uma construção cujo lugar não é o tempo homogêneo, mas um tempo saturado de 'agoras'" (BENJAMIN, 1994, p. 229).

Para melhor conhecimento de parte do passado - que diz sobre lembranças e/ou representações da educação/instrução de crianças em áreas rurais -, parece-nos importante destacar algumas indagações: qual foi - lugar ocupado pela educação pública destinada às crianças moradoras do meio rural no município de Porto Velho? As políticas de organização das escolas de Porto Velho levaram em consideração os processos formativos e os contextos vivenciados por alunos e professores das escolas rurais? Quais as concepções de infâncias que circulam nas escolas rurais?

A pesquisa tratou e refletiu sobre "valores" sociais, culturais e políticos de professoras e crianças em determinado período histórico. Acreditamos que estudos desta natureza corroboram a melhor construção e compreensão de um campo de múltiplos atravessamentos em que os discursos, tecidos nas relações sociais, revelam modos de apropriação de formas de conhecimentos, além das concepções de educação para determinado público.

A agricultura ocupou lugar de destaque no Brasil, e, de acordo com Linhares (1997), foi o setor que agregou por volta de $75 \%$ dos postos de trabalho em meados do século XX. Demais, o trabalho infantil em áreas rurais 
de alguma forma refletiv e reflete sobre os altos índices de analfabetismo no meio rural.

Não foi por acaso que o desenvolvimento econômico do Brasil foi atravessado por diversos ciclos agrários, entre eles: o café, a borracha e a exploração de madeira ilegal na Região Norte. Deste modo, as necessidades de uma rede de ensino rural se fizeram presentes no decorrer das próprias estruturas socioagrárias do país e suas especificidades no recém estado de Rondônia.

\begin{abstract}
A monocultura da cana-de-açúcar, que dominou a economia do país até a metade do século XIX, prescindia de mão-de-obra especializada. No entanto, como advento da monocultura cafeeira e o fim da escravidão, a agricultura passou a carecer de pessoal mais especializado para o setor agrícola. Outras culturas secundárias, mas de alguma importância para o setor agrícola, também tiveram um desenvolvimento crescente, decorrendo daí a necessidade de pessoal com qualificação que se pretendia fosse dada pela escola (CALAZANS, 1993, p. 15).
\end{abstract}

Essa realidade sobre a necessidade da mão de obra qualificada para o meio rural não é tão recente, porém com o crescimento dos processos de produção capitalista extensivo ao meio rural, a escola passou a ser uma das instituições em que a reprodução de uma determinada ideia de desenvolvimento financeiro se solidificou - isso a partir de programas oficiais de ensino. Nesse interim, parece-nos que a equidade social é algo secundário. A escola passou a ser um dos aparatos de reprodução capitalista de acumulação, isto é, de riquezas de uns e a miséria de muitos.

\title{
OS DOCUMENTOS NOS PROCESSOS DE INVESTIGAÇÃO EM EDUCAÇÃO
}

Os documentos consultados sobre os processos de ensino rural em Porto Velho foram acessados em diversas localidades, entre elas, destacamse as realizadas no Palácio Getúlio Vargas, no Conselho Estadual de Educação e na Secretaria de Estado de Educação. Entre os documentos, utilizamos parte da legislação educacional.

No processo de pesquisa, outras fontes foram consultadas, como, por exemplo, atas, fotografias, mapas, boletins e, principalmente, entrevistas com agentes do ensino que tenham participado dos processos de 
concepção e implantação de ações pedagógicas no meio rural. Livros, periódicos e jornais de época também foram importantes documentos averiguados a partir do focos de interesses que foram e ainda são a escola rural e as infâncias. Acessamos as coleções de obras disponíveis na Biblioteca da Universidade Federal de Rondônia (UNIR), entre outras bibliotecas públicas do município de Porto Velho. Por fim, pesquisamos bancos de dados estatísticos e demográficos.

Inicialmente, recorremos aos inventários do Arquivo Público Getúlio Vargas para identificarmos possíveis fontes sobre os processos de ensino rural em Porto Velho, Rondônia.

Todo o trabalho de identificação documental foi longo e nos exigiu maior permanência em campo para a realização de atividades contínuas. Assim, o planejamento foi essencial para o cumprimento das etapas da pesquisa e, conforme Aróstegui (2006), foi preciso mencionar o que se pretendia conhecer, como conhecer e a comprovação do conhecido.

Planejar uma pesquisa é, de certa maneira, prever os momentos cognoscitivos e técnicos pelos quais o trabalho deverá passar. Mas, de forma mais prática, planejar seria a previsão de adaptação do trabalho aos problemas concretos do objeto pesquisado. Um planejamento teria de atender a três níveis: o do que se quer conhecer, o de como conhecer e o da comprovação do conhecido. Isso acarretaria a previsão do conjunto de problemas relacionados à pesquisa - 'por que um processo é como é' -, seus limites cronológicos e sua inteligibilidade e justificação e a pergunta que é preciso formular. O como articular uma pesquisa deveria levar em consideração as fontes, a organização da informação, sua tipologia e seu uso, assim como a relação com outras pesquisas. Nenhuma pesquisa pode permanecer isolada das demais de uma mesma área (ARÓSTEGUI, 2006. p. 468).

Foi necessário o desdobramento de esforços em atividades contínuas, em campo, muitas vezes em localidades distantes e de difícil acesso. Foi dessa forma que "se depurou o material, dia após dia, peça a peça. Eu desbastara, polira, cortara e recortara, preparando cuidadosamente a montagem" (DUBY, 1993, P. 55). De fato, as considerações de Duby (1993) sintetizaram, de certo modo, o que fizemos a partir do planejamento. 
Após o tempo empreendido para a coleta das fontes documentais diversas, foi necessário um processo de "garimpagem", de decodificação e transcrição das fontes captadas nas diversas localidades.

Depois dessa etapa, estabelecemos seleção e sistematização de nossos registros com os encontros ou achados das categorias de campo.

Operamos a partir de pressupostos da triangulação, com vistas à produção de uma pesquisa que não se esgotou nos limites específicos das atividades de coleta de dados, compreendendo um esforço de investigação no interior de um projeto mais amplo de atuação, no caso, o contexto escolar que abrange fins do século XX ao início do XXI.

A investigação contemplou parte das culturas escolares do meio rural em Porto Velho. Culturas vistas como o conjunto de práticas educativas que, de alguma forma, foram transmissoras e construtoras de conhecimentos.

[...] poder-se-ia descrever a cultura escolar como um conjunto de normas que definem conhecimentos a ensinar e condutas a inculcar, e um conjunto de práticas que permitem a transmissão desses conhecimentos e a incorporação desses comportamentos; normas e práticas coordenadas a finalidades que podem variar segundo as épocas (finalidades religiosas, sociopolíticas ou simplesmente de socialização). Normas e práticas não podem ser analisadas sem se levar em conta o corpo profissional dos agentes que são chamados a obedecer a essas ordens e, portanto, a utilizar dispositivos pedagógicos encarregados de facilitar sua aplicação, a saber, os professores primários e os demais professores (JULIA, 2001. p. 10-11).

Nesse caso, as culturas impregnadas nos processos de educação rural em Porto Velho foram acessadas a partir de multiplicidades de dados coletados. O processo de pesquisa qualitativa foi inserido na pluralidade de documentos. Ressaltamos a importância dos registros, pistas ou indícios da presença de representações, de facetas do ensino rural como parte dos traços das culturas na educação em Rondônia. Isso porque a pesquisa em História da Educação demandou um trabalho de investigação de indícios, tanto na condição de materiais impressos quanto de materiais digitais. Ressaltamos a importância dos fragmentos da memória, pois "O termo 'indício' refere-se a manuscritos, livros impressos, prédios, mobília, paisagem [...] bem como a muitos tipos diferentes de imagens: pinturas, estátuas, 
gravuras, fotografias. [...] publicações e assim por diante [...] as experiências não verbais e o conhecimento de culturas passadas [...]" (BURKE, 2004. p. 1617).

Coletar e analisar parte dos vários indícios verbais e não verbais, na pesquisa de campo, permitiu estabelecer características de alguns processos educativos concernentes ao meio rural. Aliado às descobertas, apoiamo-nos no paradigma indiciário de Ginzburg que diz: "[...] se a realidade é opaca, existem zonas privilegiadas - sinais, indícios - que permitem decifrá-la" (GINZBURG, 2002. p. 177). Nessa premissa, a interpretação de documentos se fez necessária e ofereceu subsídios importantes para se pensar o lugar ocupado pelo ensino rural nos debates educacionais.

As fontes estão na origem, constitui o ponto de partida, a base, o ponto de apoio da construção historiográfica que é a reconstrução, no plano do conhecimento, do objeto histórico estudado. Assim, as fontes históricas não são fontes da história, ou seja, não é delas que brota e flui a história. Elas, enquanto registro, enquanto testemunhos dos atos históricos, são a fonte do nosso conhecimento histórico, isto é, é dela que brota, e nelas que se apoia o conhecimento que produzimos a respeito da história (SAVIANI, 2004. p. 5-6).

Ao consideramos que os testemunhos históricos também brotam de diálogos, discursos ou depoimentos de agentes do ensino e da comunidade escolar, envolvidos nos processos de ensino em áreas rurais, problematizamos os contextos da educação rural. Isso implicou encontrar referências de longa duração, sua atividade, seus significantes, seus gostos, suas maneiras, atrelados a quem os corporificou para compreender suas permanências. Le Goff (2003) nos lembrou que o documento não é inócuo; é produto de uma rede de relações estabelecidas na sociedade. O testemunho para a investigação em História e historiografia da educação foi e é fundamental para a produção de ciência.

O testemunho nos leva, de um salto, das condições formais ao conteúdo das 'coisas do passado' (praeterita), das condições de possibilidade ao processo efetivo da operação historiográfica. Com o testemunho inaugura-se um processo epistemológico que parte da memória declarada, passa pelo arquivo e pelos documentos e termina na prova documental (RICOEUR, 2007. p.170).

Revista Exitus, Santarém/PA, Vol. 10, p. 01-31, e020046, 2020 
Tanto em Le Goff (2003), quanto em Ricoeur (2007), verificamos a importância das fontes documentais para o processo de ressignificação do ensino rural.

Para auxiliar nos processos de categorização, utilizamos o software Maxqda - The Art of Data Analysis, usado em investigações qualiquantitativas. Esta ferramenta auxiliou nos processos de pesquisa a partir das diversificadas fontes coletadas. Segundo Gibbs (2009, p. 145), a utilização de softwares é importante para "armazenagem e manipulação de textos e documentos e à criação e manipulação de códigos".

\begin{abstract}
A utilização dos computadores na investigação qualitativa vai desde o simples processamento de texto até sofisticadas classificações e recuperações de dados (Tesch, 1989). A maior parte dos programas de processamento de texto têm opc,ões de procura de palavras ou capacidades de indexac,ão que permitem ao investigador localizar palavras ou códigos-chave em ficheiros de texto. Alguns programas têm gestores de bases de dados que podem ser úteis para os investigadores qualitativos. Estas são as formas mais simples de investigadores qualitativos; e as mais simples de utilizac,ão dos computadores para a classificação e recuperação mecânica. As formas mais sofisticadas e mais complexas envolvem programas especialmente concebidos para investigadores qualitativos que utilizam computadores mainframe de grande capacidade, como os grandes computadores de uma companhia ou universidade [...] (BOGDAN; BIKLEN, 1994, p. 239).
\end{abstract}

Tanto as entrevistas realizadas quanto outros documentos captados em campo foram cuidadosamente submetidos ao software Maxqda, esse procedimento viabilizou melhor sistematização dos dados e o estabelecimento de categorias de campo para as análises.

Muitos dos softwares podem ser utilizados para pesquisas qualitativas e quantitativas. Em nosso caso, a pesquisa em educação corresponde à vertente qualitativa. Deste modo, os processos de arquivamento, gerenciamento e o estabelecimento de categorias ou códigos - todos foram viabilizados a partir desta ferramenta.

Ressaltamos que a categorização ou codificação dos dados recolhidos não foi realizada de modo autônomo. Portanto, isso nos exigiu tempo, dedicação e retorno ao campo de investigação. Matias et al. (2019) 
obordaram sobre as característica e importância da pesquisa qualitativa em Educação.

\section{MODELO DE ESCOLA RURAL}

As propostas de educação destinadas à população que residem e/ou trabalham no meio rural nem sempre foram condizentes com as realidades dos sujeitos. Verificamos que muitos dos documentos coletados nas atividades de campo nos remeteram ao rural na condição de mola propulsora para a modernidade ou progresso, porém questionamos que modernidade ou progresso se pretende dentro do contexto de precarização em que se encontra grande parte das escolas rurais.

De modo geral, para a idéia de progresso ser aceita não parece suficiente apenas perceber o curso do universo como um perpétuo flux, como já fizera Heráclito de Éfeso (549-504 AC.): 'Nos mesmos rios entramos e não entramos, somos e não somos' (fragmentos 49a). Esta sentença bem expressa a idéia de devir, mas não indica um objetivo a priori, um fim, um telos. À primeira vista, a ideia de progresso parece requerer, além do fator mudança, a indicação de um objetivo último que desse sentido ao movimento (MOREIRA, 1997, p. 26).

As proposições sobre a modernidade ou progresso compõem contextos históricos e requer mudanças - foi assim na época das etapas da Revolução Industrial, na transição do Brasil Império para República. Porém, a modernidade almejada não se fez e não se faz presente no modelo de escola rural no contexto portovelhense. As marcas de um modelo de escola atrelada aos preceitos capitalistas demonstram prejuízos para o povo.

De acordo com Moreira (1997), "se nos mesmos rios entramos e não entramos, somos e não somos", não foi diferente na investigação sobre as escolas rurais. A promessa da modernidade e progresso sempre esteve presente, talvez por fatores diversos entre eles a própria inserção de Rondônia na demanda capitalista em curso, seja por meio da exploração da borracha, seja por intermédio da agricultura, pecuária entre outros, mas não no modelo de uma escola necessária.

Na maioria das vezes a opção do poder público é pelo fechamento das escolas, algo contrário aos preceitos da modernidade. Nascimento et al. 
(2020, p. 17) mencionaram que "fechar escolas é crime, todavia, é algo muito comum na realidade do campo brasileiro. Como denunciado pelos dados do censo escolar, mais de 37 mil escolas no campo foram fechadas nos últimos 15 anos no país". Muitas são as dificuldades para os estudantes das escolas rurais, mas fechar escolas não é a saída.

Encontramos nas falas dos colaboradores entrevistados exemplos de culturas em que por um lado externa-se o novo, mas por outro as ações efetivas do poder público acentuaram complexas relações entre a comunidade e a escola rural. A escola no centro das atenções é de fato uma das importantes instituições para agregar, socializar, produzir e comunicar ciência e, consequentemente, disseminar bens culturais.

A seguir, um dos mapas produzidos por meio de entrevistas junto a alunos de escolas rurais do distrito de Porto Velho. Nos registros, não trouxemos as identidades dos sujeitos.

Optamos pela inserção dos colaboradores a partir da constatação de confrontos entre o modelo de escola instituído e as dificuldades externadas sobre o acesso a materiais didáticos e ausências de aulas por fatores técnicos (falta de energia e/ou falta de sinal de internet).

Os cinco destaques dizem respeito, respectivamente, aos processos de aprendizagem em sala de aula; à importância do professor no processo de formação; aos materiais pedagógicos; ao acesso à internet em casa e dificuldades para estudar. Ao indagarmos colaboradores das escolas rurais sobre os modelos de escola e seus vínculos com o modo de produção capitalista, surgiu a proposição de verificar o quanto ainda é desprezivel a atenção de agentes públicos em relação às escolas situadas em área rural nos distritos de Porto Velho. Deste modo, a sistematização sobre as condições em que o ensino é oferecido e as necessidades dos educandos apresentam-se em conflitos. 
Figura 1 - Dificuldades dos estudantes

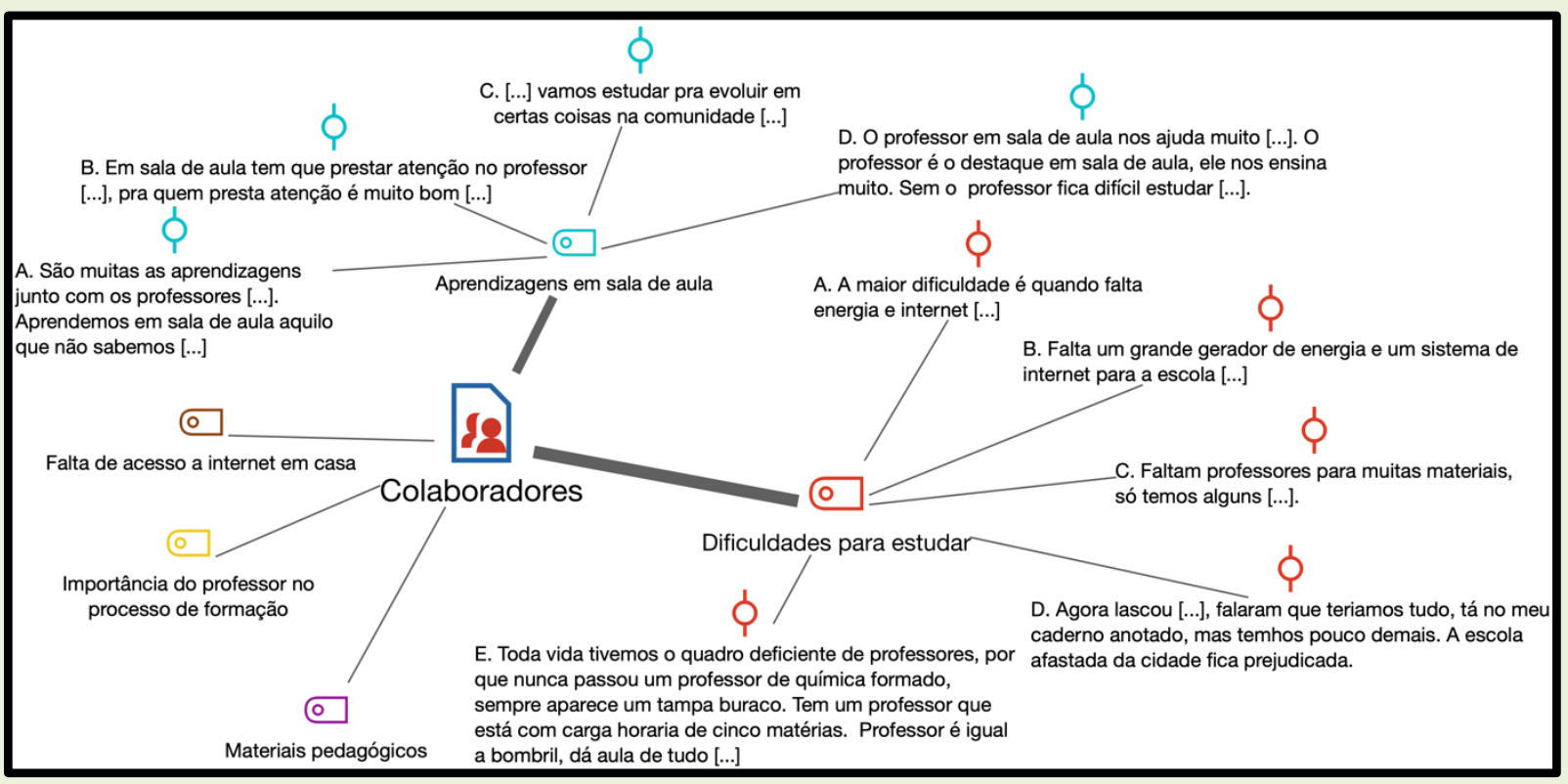

Fonte: Os autores com recurso do software Maxqda.

$\mathrm{Na}$ figura acima, verificamos nas linhas mais acentuadas as recorrências de temas nas falas dos colaboradores entrevistados. Deste modo, muitas foram e são as dificuldades para estudar em sala de aula no meio rural. Na mesma linha de pensamento, as aprendizagens em sala de aula e a presença física do professor são mencionadas como significativas para os avanços dos discentes no interior das escolas rurais.

Diante do contexto neoliberal de contenção de recursos financeiros destinadas a setores sociais e dificuldades dos professores para a efetivação de ações pedagógicas necessárias, é que o projeto de escola se revela, uma educação com viés burguês, muitas vezes técnica e distante das realidades dos rurícolas.

De acordo com Barros (2016) e os dados recolhidos em campo, há muitos desafios: desde a falta de materiais pedagógicos que inviabiliza o acesso a bens culturais até a ausência de docentes, substituídos pelo chamado projeto Ensino Médio com Mediação Tecnológica, Lei n 3.346, de 4 de julho de 2016, do governo de Estado de Rondônia.

Art. $1^{\circ}$. Fica instituído o Projeto Ensino Médio com Mediação Tecnológica no âmbito da Secretaria de Estado da Educação SEDUC, com o objetivo de implantar o Ensino Médio com Mediação 
Tecnológica aos estudantes que residem na zona rural, cujas localidades são de difícil acesso, com demanda reprimida ou em localidades onde houver carência de profissionais habilitados (RONDÔNIA, 2016).

A legislação acima estabeleceu critérios para a implementação da Educação Tecnológica em escolas rurais. Assim, menciona que o acesso às escolas é fator preponderante para viabilizar o modelo de ensino. Uma das ideias propagadas pelo poder público para a implantação desse modelo de ensino é a carência de professores habilitados, porém as autoridades públicas não se interessaram em debater possíveis projetos ou programas de formação inicial de professores junto à Universidade Federal de Rondônia UNIR, tampouco melhoria no plano de carreira e alojamento para permanências de professores nas distantes áreas em que as escolas rurais estão localizadas.

É pertinte lembrarmos que Carvalho et al. (2019, p. 179) mencionaram que "a década de 1980 representou para os educadores o marco de crítica e reação ao pensamento tecnicista [...]", mesmo com todas as críticas a proposição de uma escola tecnicistas, percebemos que a escola rural é considerada pelo poder público unicamente pela vertente tecnicista.

Outro ponto diz respeito à falta de justificativas teórico-metodológica por parte das administrações públicas para efetivar a Educação Tecnológica em escolas rurais. Em nossas investigações, em bases de dados, - a exemplo da Biblioteca Digital Brasileira de Teses e Dissertações (BDTD) e o Catálogo de Teses e Dissertações da Coordenação de Aperfeiçoamento de Pessoal de Nível Superior (CAPES), que disponibilizam resultados de pesquisas científicas -, não encontramos justificativas científicas que amparem as ações do projeto Ensino Médio com Mediação Tecnológica, Lei n 3.346, de 4 de julho de 2016, implementada pelo governo de Estado de Rondônia.

A Lei de Diretrizes e Bases da Educação Nacional, Lei n 9.394, de 20 de dezembro de 1996 - LDB, ao tratar do direito à educação e do dever de educar, estabelece que:

Art. $4^{\circ}$. O dever do Estado com a educação escolar pública será efetivado mediante a garantia de: 
I - ensino fundamental, obrigatório e gratuito, inclusive para os que a ele não tiveram acesso na idade própria;

II - progressiva extensão da obrigatoriedade e gratuidade ao ensino médio:

III - atendimento educacional especializado gratuito aos educandos com necessidades especiais, preferencialmente na rede regular de ensino:

IV - atendimento gratuito em creches e pré-escolas às crianças de zero a seis anos de idade;

$\checkmark$ - acesso aos níveis mais elevados do ensino, da pesquisa e da criação artística, segundo a capacidade de cada um;

VI - oferta de ensino noturno regular, adequado às condições do educando;

VII - oferta de educação escolar regular para jovens e adultos, com características e modalidades adequadas às suas necessidades e disponibilidades, garantindo-se aos que forem trabalhadores as condições de acesso e permanência na escola;

VIII - atendimento ao educando, no ensino fundamental público, por meio de programas suplementares de material didático-escolar, transporte, alimentação e assistência à saúde;

IX - padrões mínimos de qualidade de ensino, definidos como a variedade e quantidade mínimas, por aluno, de insumos indispensáveis ao desenvolvimento do processo de ensinoaprendizagem (BRASIL, 1996).

A LDB traz diversos e importantes itens sobre as características de um modelo de escola que tenha condições necessárias para a garantia do processo de ensino e aprendizagem nas escolas, sem distinções para escolas rurais e/ou urbanas.

Já a Lei $n^{\circ}$ 3.346, de 4 de julho de 2016, também aborda as características para implementação de um modelo de escola. Nela, percebemos que, - entre os itens mencionados a partir das competências da Coordenador Pedagógico da Coordenadoria Regional de Educação -, há a ideia pelo menos na letra da lei de acompanhamento in loco das ações desenvolvidas. No entanto, as escolas rurais visitadas por nós em distritos de Porto Velho não apresentaram condições básicas de oferta de equipamentos técnicos e tecnológicos para viabilizar o projeto Ensino Médio com Mediação Tecnológica. Além disso, os poucos equipamentos tecnológicos para a utilização por parte dos discentes apresentaram problemas de ordem técnica, ou seja, o sistema operacional dos equipamentos - computadores estavam defasados, e, em muitos casos, os equipamentos não acessavam a internet e, consequentemente, aos conteúdos necessários para viabilizar as atividades de ensino e 
aprendizagem a distância. Por esses e outros exemplos, pode-se constatar que o acompanhamento in loco não se solidificou.

Art. 5. São competências do Coordenador Pedagógico da Coordenadoria Regional de Educação:

I - acompanhar o desenvolvimento do Projeto in loco assegurando sua viabilidade dentre as especificações referentes à clientela e localidade das escolas de difícil acesso;

II - monitorar e acompanhar os resultados obtidos pelos estudantes do Ensino Médio com Mediação Tecnológica;

III - manter o calendário atualizado de visitas às escolas sedes e extensões com salas de aula com Mediação Tecnológica;

IV - oferecer orientação e assistência ao professor presencial;

$\checkmark$ - garantir que as avaliações e plano de estudo cheguem à escola sede em tempo hábil para serem aplicadas pelo professor presencial;

$\mathrm{VI}$ - monitorar as escolas pólos para verificar suas reais necessidades, como espaço ambiente, recursos técnicos e humanos, dentre outros; VII - fornecer ao professor presencial materiais didáticos, quando necessário:

VIII - participar e intervir junto à direção na organização do trabalho pedagógico escolar das salas de Ensino Médio com Mediação Tecnológica;

IX - providenciar certificação dos estudantes na conclusão do curso, em conjunto com a escola sede; e

$X$ - encaminhar relatório sucinto à Coordenação do Projeto na SEDUC ao final de cada componente curricular, por módulo, e relatório geral no final de cada ano escolar (RONDÔNIA, 2016).

O Artigo $5^{\circ}$ em seu inciso VII, da Lei $n^{\circ} 3.346$, de 4 de julho de 2016 , menciona sobre o fornecimento de materiais didáticos aos professores. Esse ponto nos permite problematizações diversas, entre elas inferimos sobre de quem é a competência de oferecer e permitir acesso aos materiais pedagógicos para discentes e docentes? Na investigação que realizamos, não presenciamos em nenhum momento o uso de materiais didáticos oferecidos pela administração pública. Verificamos, nela, o quanto os estudantes e professores necessitam desses materiais.

Os fragmentos de legislações nos permitem inferir o quanto a garantia dos direitos sociais ainda se faz necessário. Não se pode afirmar que no Brasil há uma linearidade cronológica entre situações histórico-sociais - que reservem para si peculiaridades próprias. A educação na condição de direito é uma das prerrogativas constitucionais importantes, pois recebeu a formulação direito de todos e dever do Estado. 


\section{INFÂNCIAS DO RURAL EM DEBATE}

A partir das entrevistas semiestruturadas, realizadas junto aos colaboradores professores e professoras sobre as concepções de infâncias percebidas no interior das escolas, encontramos diversidade de entendimentos, nem sempre conceituais.

Quem quer que se ocupe com a análise das concepções de criança subjazem quer ao discurso comum que à produção centrada no mundo infantil, rapidamente se dará conta de uma grande disparidade de posições. Uns valorizam aquilo que a criança já é e que a faz ser, de facto, uma criança: outros, pelo contrário, enfatizam o que lhe falta e o que ela poderá (ou deverá) vir a ser. Uns insistem na importância da iniciação ao mundo adulto; outros defendem a necessidade da proteção face a esse mundo. Uns encaram a criança como um agente dotado de competências e capacidades; outros realçam aquilo de que ela carece (PINTO, 1997, p.33).

Para nós, defendemos as dimensões sociais da infância, ou seja, um conjunto de processos sociais, mediante os quais a infância emerge como realidade social. A realidade corresponde aos contextos em que há entrelaçamentos com a própria sociedade.

Nos fragmentos de entrevistas, não utilizamos os nomes dos professores e das professoras. Deste modo, manteremos os preceitos éticos sobre a pesquisa em educação. Lembramos que "os gestos também intervêm e seguem convenções. Toda troca de palavras envolve um jogo ritual. Toda enunciação e sua escuta são acompanhadas de gestos mais ou menos controlados por seus autores" (MACHADO, 2002, p. 49).

Em uma das entrevistas, constatamos que de imediato não há diferenciação entre o que é ser criança da cidade e do meio rural. A infância rural é percebida como um tempo de aprender, e, sob esse viés, poucos são os protagonismos das crianças. A criança vista por meio de suas possibilidades de aprender.

A infância na escola rural pra mim é um eixo que vai despertar na criança um desejo de aprender, um desejo que ela vai a primeira vez para a escola, porque o objetivo dos professores é que elas se adaptem bem né? E continue gostando e se desenvolva cada dia mais nos estudos, na aprendizagem. Pra mim, a infância rural no interior da escola é valorizada mais do que na rua (Colaboradora 1. Porto Velho, 20 de setembro 2018. Entrevista concedida aos autores). 
A colaboradora 1 afirma, no debate, que a criança do meio rural, pelo menos as que cotidianamente frequentam a escola, possuem valoração diferenciada em relação às crianças da rua, ou seja, das crianças do meio urbano - em nenhum momento essa valoração é mencionada de modo que haja melhor entendimento sobre o que de fato assegura as pluralidades, as infâncias. Na sequência a colaboradora menciona que as crianças da zona rural são iguais as crianças da zona urbana.

As crianças da zona rural não têm nada de diferente da zona
urbana, o que acontece aqui é que muitas vezes o professor se doa,
trabalhar, desperta, só que em muitos casos os pais não colaboram,
não contribuem, deixam muito a desejar. Isso deixa uma carga muita
grande para o professor, para ele agir com todas as dificuldades. A
falta da presença dos pais na escola para o acompanhamento das
crianças atrapalha. Também falta o acompanhamento em casa
(Colaboradora 1. Porto Velho, 20 de setembro 2018. Entrevista
concedida aos autores).

No fragmento de entrevista, é perceptível que, na voz da colaboradora 1, a infância no meio rural é a mesma em relação ao meio urbano. A falta de distinção das especificidades de ser criança em seus vários espaços de vida nos alerta para um modelo de infância único, modelo que normalmente é percebido como o de seres incapazes, incompletos e pouco sábios. O debate se volta para os adultos, - aqueles que são os responsáveis pelas crianças. Assim, o sentido que se aponta nos faz lembrar que o procedimento de assistências das crianças, seja em casa, ou na escola, é fator primordial para viabilizar melhorias nos processos de ensino e aprendizagem. Por um lado, os pais se ausentaram no acompanhamento de seus filhos sobre os afazeres da escola; por outro lado, a escola imersa em problemas de toda ordem pouco traz ao debate as necessidades materiais de sobrevivência das famílias que não são possuidoras dos meios de produção e dependem do próprio trabalho para "ganhar a vida". Em sua maioria, as famílias do entorno da escola são pobres e necessitam do trabalho para a sobrevivência, muitas vezes insalubre. 
Se o trabalho desenvolvido pelas famílias se caracteriza por ser insalubre, indagamos quais os entendimentos da relação entre escola, trabalho, família e ser criança?

[...] nessa nossa comunidade aqui, é uma comunidade normal talvez, o povo trabalha em um lugar muito insalubre, trabalho tão árduo, eles terminam assim, sem entusiasmo, sem estímulos, já que não tem autoestima, não tem como ajudar a criança. As crianças são normais, as crianças aprendem, mas tem muitos casos que se deixam a desejar, mas não é culpa das crianças nem dos professores (Colaboradora 1. Porto Velho, 20 de setembro 2018. Entrevista concedida aos autores).

As crianças são normais, a comunidade é normal, o que não é normal é o trabalho insalubre. Parece-nos que a concepção de infâncias em sua, pluralidade não é pertinente aos olhos da colaboradora, tudo é igual, aqui e acolá não se distingue, o rural e o urbano correspondem a mesma coisa. Constatamos que a ausência da ideia de infância repleta de saberes é o convencional.

Os professores estão isentos das culpas sobre as inadequações sociais que atrapalham a aquisição de conhecimentos por parte das crianças. Afinal quem são os agentes causadores de tantos problemas sociais? As crianças do meio rural não possuem características específicas, pelo menos esse foi o posicionamento.

Não há nenhuma característica específica das crianças na escola rural. Ser criança na escola rural talvez seja assim: é uma criança que talvez tenha muitos privilégios em relação a outras crianças da rua, porque as crianças no campo são mais livres, brincam de modo diferente, com a natureza, acompanham a natureza, muitas vezes é o banho na chuva, é o passear no mato, é respirar aquele ar puro (risos), é que na cidade é difícil né. Ser criança na zona rural é privilégio né (Colaboradora 1. Porto Velho, 20 de setembro 2018. Entrevista concedida aos autores).

As crianças do meio rural são possuidoras de privilégios, todos relacionados à natureza, ou seja, tomam banho na chuva, passeiam no mato, respiram ar puro entre outros. Mas em nenhum momento são vistas com característica que de fato asseguram o direito de ter direitos, inclusive o direito de assistência advinda do poder público diante dos baixos rendimentos escolares. 
A concepção de criança no meio rural é idêntica às do meio urbano, embora por aqui haja privilégios relacionados à natureza. Indagamos se os privilégios das crianças do meio rural são suficientes para assegurar uma educação dialética e detentora de direitos? Algumas crianças trabalham e estudam ao mesmo tempo. "Apesar de ser proibido, o trabalho infantil acontece, sempre acontece que as crianças estão no trabalho. Aqui não tem trabalho na roça, é o trabalho da coleta seletiva, trabalham com o lixo, a matéria prima das crianças é o lixo" (Colaboradora 1. Porto Velho, 25 de março 2019. Entrevista concedida aos autores). A criança e a natureza, uma simbiose externada por Lauwe (1991, p. 275): "a natureza nem sempre é percebida globalmente. Os elementos que a compõem são frequentemente associados à criança, segundo um simbolismo clássico. Encontramos uma identidade de natureza entre tal elemento particular e uma imagem de criança".

O ser criança e o ser adulto, pontos e contrapontos, quais as características das etapas de cada época?

\begin{abstract}
Ser criança pra mim é a criança que estuda e desenvolve, que acompanha todas as fases da vida, e ser adulto talvez ele quer seguir outros caminhos, as vezes não vai pelo caminho certo também, e termina se perdendo né! Então a diferença entre criança e adulto é isso, ela se desenvolver, são as fases normais, chega lá na frente e tem o livre arbítrio né, as vezes não é a coisa tão boa pra ser para ele (Colaboradora 1. Porto Velho, 20 de setembro 2018. Entrevista concedida aos autores).
\end{abstract}

A colaboradora menciona no fragmento de entrevista que ser criança corresponde ao desenvolvimento das fases da vida, mas, em nenhum momento, estabelece vínculos da infância com suas especificidades. A fala nos reporta aos tempos.

Falar de infância é falar de tempo. A infância costuma ser pensada como início de algo. Ponto de partida de uma vida que vai se transformando à medida que avança na conquista de seu tempo. Enquanto isso acontece, quem transita por esse caminho vai se afastando paulatinamente do início, vai abandonando a infância. Assim, a infância é o lugar de onde os adultos provieram e, por isso mesmo, a promessa de renovação do nosso futuro como espécie, A infância é como passado e nosso futuro ao mesmo tempo (OLARIETA, 2015, p. 30). 
As infâncias vistas, percebidas, entendidas e concebidas. De fato, falar de infância é falar de tempo, mas quais os tempos das infâncias no meio rural? Presente, passado ou futuro? Uma infância que se anuncia minimamente, ainda acanhada, pouco expressiva aos olhos daqueles que trabalham no interior das escolas rurais.

\begin{abstract}
Infância é a passagem pelas fases normais, é o que agente não vê muito aqui, porque as crianças não têm infância, aqui nós temos do $1^{\circ}$ ao $5^{\circ}$ ano né, eles começam a trabalhar muito cedo, tem caso que os pais levam as crianças para o trabalho. Desde cedo eles partem para o trabalho, pela necessidade, outros pelo incentivo de ver uns trabalhando, e querem ir também (Colaboradora 2. Porto Velho, 20 de setembro 2018. Entrevista concedida aos autores).
\end{abstract}

Novamente percebemos que a infância se revela aos olhos da colaboradora como uma passagem pelas fases normais. Porém, na localidade, as crianças não são portadoras de infância. Isso ocorre porque o trabalho é uma das condições prioritárias para a sobrevivência. O tempo da infância em contraposição com o tempo do adulto, mesmo com a idade de criança, os pequenos tiveram a infância arrancada.

A infância do meio rural é vista com certo prejuízo em relação à escola. Segundo a colaboradora, os pais não participam dos processos de ensino e aprendizagem de seus filhos por vários motivos, entre eles, dedicam muito tempo ao labor - não possuem condições efetivas para ensinar seus filhos, talvez por serem analfabetos.

Na aprendizagem as crianças do meio rural são iguais as crianças do meio urbano. A diferença é na família, as famílias aqui no meio rural não têm esse compromisso com as crianças, a maior dificuldade de aprendizagem que encontramos é a falta do acompanhamento familiar, além dos pais serem analfabetos, não tem incentivo e compromisso com a escola. Os pais não estão nem aí para a escola (Colaboradora 2. Porto Velho, 20 de setembro 2018. Entrevista concedida aos autores).

A família do meio rural demonstra pouco compromisso diante da fala da colaboradora. Neste ponto, há uma valoração do meio urbano como lócus da solução de diversos problemas, mas em nenhum momento os fatores sociais são debatidos a nível das reponsabilidades do poder público. 
Parece-nos que a escola a todo custo faz o que pode para atender seu público.

A maior parte das reflexões trazidas por meio dos depoimentos nos permitem inferir que o fator preponderante é o trabalho das crianças e a desassistência das famílias em relação ao acompanhamento de seus filhos nos assuntos da escola.

É mais difícil trabalhar com uma criança da zona rural, porque não tem incentivos dos pais, na zona urbana os pais são comprometidos. Diferente da zona urbana, os pais da zona rural não têm compromisso com a escola, talvez porque eles trabalharem muito né ou pela formação que possuem (Colaboradora 2. Porto Velho, 20 de setembro 2018. Entrevista concedida aos autores).

As dificuldades apontadas para o exercício da docência junto às crianças da escola rural são prontamente colocadas na balança. Aqui, parece-nos que as referências de uma escola modelo historicamente advêm da cidade. A cidade aparentemente é o local em que os pais talvez tenham menos afazeres e, portanto, são mais participativos, frequentam a escola de seus filhos pequenos e consequentemente são considerados integrantes do processo de ensino e aprendizagem. Uma ilusão!

A escola de hoje nos faz rememorar outros tempos - assim como destacam Barros; Afonso Moreno (2016, p. 261). Estes mencionam que "nos primeiros anos da proclamação da República, a política para a infância pobre foi de fato decorrente da vertente liberal e da correlação de forças do bloco hegemônico, das elites agrárias". Nesse sentido, indagamos: a infância de hoje é decorrente de quê?

Amparados na ideia de ruptura estabelecida na obra de Aries (2006) sobre a infância, é perceptível que o sentimento moderno de infância se apresenta em confronto para os adultos, por um lado a criança é considerada um ser inocente, puro, ingênuo - paparicação; por outro, lado, a criança é entendida como imperfeita ou incompleta, que necessita de um processo de ensino estabelecido pelos adultos. 


\section{POLÍTICA DE EDUCAÇÃO RURAL}

Falar de crianças em escolas rurais em Rondônia é conferir importância a grupos de atores sociais, muitas vezes desprezados diante de ações das administrações públicas que elegeram a cidade na condição de modelo para o ensino, além disso consideram a criança com a fixidez do pensamento que não se remete aos valores sociais.

A condição das crianças no mundo contemporâneo, mais que motivar os historiadores à reflexão, instiga-os a olhar cada vez mais fundo nos olhos da história, em busca do aflorar de uma nova consciência. Consciência, capaz de reformular atitudes em relação à infância, de rever valores sociais, de identificar prioridades reais, de superar, enfim, a enorme fratura econômico-social que ainda se impõe às crianças neste recém-iniciado século XXI (MOURA, 2007, p. 43).

Olhar cada vez mais fundo na investigação significou, em nosso caso, verificar a construção e solidificação do Estado de Rondônia, principalmente em seus aspectos que tangenciaram os processos de educação no meio rural para as crianças - o que não nos isenta de analisarmos os debates atuais sobre a implementação do projeto Estadual, denominado "Ensino Médio com Mediação Tecnológica", voltado para as escolas situadas em áreas rurais.

Do ponto de vista da estrutura organizacional dos municípios rondonienses e suas responsabilidades para com o direito social que é a educação das crianças, identificamos diversas dificuldades para se promover a educação destinada aos povos que vivem em áreas rurais: 1) seja pelo desconhecimento das Diretrizes Operacionais para a Educação Básica nas Escolas do Campo - Brasil (2002), seja pela ausência de políticas públicas adequadas aos rurículas; 2) seja pela incipiente remuneração do professorado das escolas básicas do meio rural, seja pelo precário plano de carreira dos trabalhadores em educação; 3) seja pela falta de materiais pedagógicos necessários e adequados às realidades das crianças do meio rural, seja, enfim, pela precariedade da mobília e má condição das instalações das escolas entre outros. Essa realidade ainda se faz presente em muitas localidades de Rondônia e do Brasil, e envolve crianças e jovens. 
Nas pesquisas realizadas por Bof (2006), notamos o contexto da educação rural rondoniense atrelado aos processos de concentração fundiária, e ao crescente êxodo rural. Dessa forma, muitas crianças e jovens saem de suas regiões de origem junto a seus familiares para se readequarem a intensa urbanização. São forçadas a deixarem o meio rural.

Nos dados estatísticos disponíveis pelo IBGE, encontramos no censo demográfico de 2014 diversos indicadores sobre o fechamento de escolas em Rondônia, em comparação no ano de 2007, havia o total de 1.782 escolas de educação básica, já em 2014 verificamos o número de 1.336 escolas, ou seja, houve o fechamento de 446 escolas, em sua maioria escolas no meio rural. Os dados estatísticos são anunciadores de diversas indagações, entre elas, destacamos a emergências de compreendermos os motivos pelos quais as políticas de inserção das crianças e jovens aos processos de alfabetização e escolarização ainda são reduzidas.

As escolas públicas rurais ainda fazem parte de uma triste estatística em que há ausências de muitas coisas, desde materiais didáticos específicos a sistemas de refrigeração compatíveis com as localidades de elevadas temperaturas como a região Norte do Brasil. Também não é comum a existência de quadras e/ou pátios cobertos para os alunos realizarem suas diversas atividades. Muitas escolas rurais de Educação Infantil e Ensino Fundamental de Porto Velho não poussem brinquedos para as crianças. Esses fatores também nos apontam para as fragilidades quando o assunto é políticas públicas e suas vertentes educacionais.

As políticas de saúde, educação, habitação, trabalho, assistência, previdência, recreação e nutrição são objeto de luta entre diferentes forças sociais, em cada conjuntura, não constituindo, pois, o resultado mecânico da acumulação nem a manutenção exclusiva do poder das classes dominantes ou do Estado. Essas políticas não caem do céu, nem são presentes ou outorga do bloco do poder. Elas são ganhos conquistados em duras lutas e resultados de processos complexos de relação de forças. As lutas pela saúde, pela educação, pela habitação, pela previdência atravessam os diferentes grupos das classes dominadas e se traduzem em movimentos bastante diversificados, envolvendo diferentes organizações, como os sindicatos, as associações, as instituições e os partidos (FALEIROS, 2006, p. 62). 
A política de educação está inserida em contexto maior, já que faz parte de um bloco de forças sociais que ora sobressai, ora é vencida pelas forças de produção capitalista junto à classe dominante. É dentro do debate sobre as políticas públicas que a escola rural está imersa em desafios constantes e históricos. Matias; Barros (2019) discorreram sobre os entrelaçamentos dos direitos sociais, concepção de Estado e educação.

Nas atividades de coleta de dados de campo, ficou-nos nítido que as escolas rurais ocupam lugar secundário no complexo contextos das políticas públicas educacionais.

Diante de um dos exemplos da morosidade da administração pública em relação ao atendimento das necessidades da escola rural, percebemos que há de fato uma burocratização que em muitos casos excede o normal, mas se trata de escola rural, algo característico. Sobre a manutenção da escola, percebemos a saga de um colega professor.

Há uma equipe de manutenção que é a equipe do Sr. A. que faz essa atividade de reparos, eles vieram, mas são coisas bem práticas, eles trocam uma tomada, remendam um fio que está em curto, mas trocar o material (fiação) original não. Nossa rede elétrica é antiga, defasada, remendada que não traz segurança nem qualidade para o serviço [...] precisamos de nova parte elétrica para instalação das centrais de ar, no ano passado instalamos uma central de ar, faltam mais cinco centrais [...]. A secretaria da educação ministra cursos onde há falas bem preocupadas, eu não vou culpar os técnicos em suas falas, mas o sistema, a burocratização política. Essas políticas públicas que regem a escola rural, elas são muito burocráticas e distantes ainda do atendimento real. Por exemplo, a gente precisa de uma lâmpada, a SEMED poderia disponibiliza isso através do almoxarifado, mas existe a política. Preciso enviar um ofício para lá, esse ofício vai para o gabinete de secretario, que volta para o gabinete do almoxarifado, que vai para o diretor do almoxarifado, que quando chegar no almoxarifado já dev em julho, agosto, e essa lâmpada ainda não chegou aqui. Essa burocratização que dificulta, qualquer locomoção que tenha da secretaria SEMED para a localidade rural, mesmo aqui que é perto de Porto Velho eles solicitam diária de viagem, e essa diária demora para ser liberada, para entregar, para buscar, para fazer qualquer coisa, então o sistema burocratiza muito e acaba ficando longe o atendimento (Colaborador 3. Porto Velho, 11 de março 2019. Entrevista concedida aos autores).

A escola rural é bem precária, suas salas de aula não possuem centrais de ar condicionado, aparelhos necessários diante das elevadas 
temperaturas em que crianças, jovens e adultos enfrentam no interior das salas de aula.

Na fala do colaborador, a Secretaria Municipal de Educação - SEMED de Porto Velho, carrega por meio de seus representares alguns posicionamentos coerentes ao ministrarem cursos de formação para os demais professores. Mesmo assim, esse posicionamento não é suficiente para solucionar os problemas práticos no interior das escolas rurais. Muitos desafios enfrentados, desde as longas distâncias em relação ao centro urbano do município até a burocratização para a liberação de uma simples lâmpada. Secchi (2013) nos demonstra que há um jogo estabelecido para o atendimento das necessidades da sociedade, mesmo que regularmente instituídas as políticas públicas necessariamente não são contempladas. $O$ caso acima mencionado é bem característico do desprezo das autoridades em relação às escolas rurais, que cotidianamente são renegadas em seus direitos.

A situação de desprezo em que as escolas rurais se encontram tem raízes históricas. Não por acaso, Barros (2013) alerta para a recorrência de problemas concentrados na mesma vertente: a invisibilidade da escola rural, o descumprimento da legislação, o pacto entre agentes administrativos e a burocratização das ações necessárias para minimizar as mazelas enfrentadas nos cotidianos das escolas rurais. As ações sociais são, de certo modo, bloqueadas quanto ao atendimento da classe trabalhadora.

\footnotetext{
Elemento decisivo e sempre reutilizado é a difusão de que somos um povo pacífico e ordeiro e que vive numa terra abençoada por Deus e pela natureza. Mito que esconde o país inaceitável e triste, contaminado pela doença romântica, e com uma formidável capacidade para produzir leis e não implementá-las (BEHRING; BOSCHETTI, 2011, p. 181).
}

Brasil, um país de muitas leis; um país em que os direitos sociais oscilaram ao longo da história. Um país onde se faz necessário políticas setorizadas para as escolas rurais, mas afinal o que são políticas públicas? São constituidoras de dois elementos fundantes: intenção pública e atendimento a um determinado problema público. Em nosso caso, as 
escolas públicas rurais necessariamente não foram pensadas e construídas por meio das ações do poder público. Um dos exemplos é a escola rural localizada nas imediações do Porto Velho, a qual foi erguida pelos esforços de um professor e da comunidade como forma de priorizar a educação. Em situação de normalidade, a construção da escolar é de responsabilidade da Secretaria Municipal de Educação, e não de professores e comunidade. Esse é um dos muitos casos que reunimos na condição de investigações sobre as escolas no meio rural no estado de Rondônia, região Norte do Brasil.

A história da escola é a seguinte: foi fundada em novembro 1959. Em 17 fevereiro de 1999, a escola foi transferida da beira do Rio Madeira para terra firme, o primeiro dia de aula foi perto da igrejinha, uma sala de aula coberta de papelão e lona. Em 1998 fiz um documento para o delegado de educação da $1^{a}$ delegacia, solicitando o remanejamento da escola para cá. Eu passava aqui na estrada/linha em direção a escola e via muitas crianças que não estudavam porque os pais vinham para cá trabalhar no lixão e não podiam deixar as crianças só. Um dia eu parei, fiz um levantamento, e como lá na beira do Rio Madeira não tinha mais crianças, eu pensei, não vou deixar a escola morrer, vou fazer um documento e levá-la para perto da comunidade, onde tem gente para estudar. Eu fiz um documento e o delegado assinou, nós começamos aqui a dar aulas. Nos viemos para cá e começamos a trabalhar para fazer companha no intuito de levantarmos materiais para a construção da escola, esse bloco foi construído pela comunidade. De acordo com a lei o governo não pode construir perto do lixão, mas se a comunidade construir ninguém vem derrubar. Corremos atrás de todo mundo, atrás de areia, cimento e etc.[...] um outro colega professor veio aqui e disse assim para mim: 'eu vou fazer uma campanha em Porto Velho, em todos os colégios do Estado, vou solicitar que cada um dos alunos possa doar um tijolo'. Ao todo arrumamos 12.000 tijolos, conseguimos um caminhão e buscamos os tijolos, isso foi no ano de 2000 e se estendeu até o ano de 2003 quando mudamos para cá. Um dava um dinheirinho, comprava uma carne ali, um refrigerante, e a mão de obra era daqui mesmo da comunidade. Nos desenhamos, eu e outro professor, eram só nós dois na época. Desenhamos, não somos engenheiros, medimos 20 metros por 13 de largura. Do jeito que nós desenhamos tá aí a escola de pé até hoje, sem engenheiro, foi construída com a força da comunidade. Hoje a construção está fora dos padrões, nós construímos, daí a prefeitura assumiu e há algumas melhorias (Colaborador 4. Porto Velho, 11 de março 2019. Entrevista concedida aos autores).

Uma escola é construída a várias mãos, a partir dos esforços da comunidade e de uma expertise de quem sempre deu aulas no meio rural, um professor, uma escola erguida com muitas dificuldades. A construção de uma escola se dá a partir do interesse da comunidade local, da 
solidariedade de muitos alunos dos sistemas de ensino participes da campanha que doaram tijolos.

O desenho da escola, ou seja, a planta da escola nos chama atenção: um bloco de salas de aula erguido para abrigar crianças, construção básica sem acabamentos, mas que serviu e serve para materializar o fazer da escola. A escola até hoje não recebeu subsídios financeiros e nem intervenções do poder público para melhorias significativas. A escola anda na contramão das políticas públicas, é fruto de uma teimosia do povo, uma comunidade simples que se dispôs a acompanhar as ideias de um professor. Secchi (2013) e Behring; Boschetti, (2011) apontam para os desafios a respeito do estabelecimento de políticas públicas. No exemplo acima podemos destacar que as ações do poder público serviram apenas para autorizar a mudança de local físico da escola e na sequência oficializar uma escola erguida diretamente com dinheiro do povo, ou seja, de muitos populares. Diante do exposto inferimos que a escola pública rural foi e é um foco de resistência por direito a educação.

Políticas públicas, poder público e escola rural formam uma tríade nada convencional a começar pelos distanciamentos ou não cumprimentos das responsabilidades do poder público por meio de ações necessárias para as escolas rurais - ações estas que denominamos como políticas públicas.

A partir da emergência da criação de um estado - Rondônia no início dos anos 80 do século XX, é que o poder público de fato começa a organizar de modo autônomo suas secretarias.

Um recém estado, com fortes características rurais, uma população advinda de várias localidades do Brasil a partir de um intenso fluxo migratório. O processo de ocupação das terras de Rondônia, incentivado pelo poder público, necessariamente, não cumpriu com trâmites necessários para assegurar os direitos sociais - escola rural de qualidade. Acima, externamos uma escola que funcionava às margens do Rio Madeira, foi transferida para outra localidade sem o apoio das administrações públicas, erguida com papelão e lona, mas solidificada por desenhos e sonhos de um professor. Essa é uma das realidades quando inferimos sobre o ensino rural. 


\section{CONSIDERAÇÕES}

A análise dos documentos referentes à temática educação rural, ações pedagógicas e infâncias permite inferir que $O$ ensino rural portovelhense não foi concebido a partir das necessidades de professores, alunos e comunidades.

O processo histórico de sucateamento do ensino rural foi percebido como uma das plataformas de manutenção do sistema de dominação capitalista, ou seja, a educação emancipatória sequer foi mencionada ou defendida como critério de modernidade.

Notamos que as condições de trabalho dos professores rurais não são as melhores, há muitas lacunas no que se refere às obrigações das administrações públicas. As escolas rurais carregam problemas de infraestrutura, ausências de materiais didáticos pedagógicos e muitas vezes falta o próprio professor, substituído por um projeto pouco viável em termos das ações pedagógicas necessárias para garantir os processos de ensino e aprendizagem.

Em virtude do desleixo do poder público, atinentes às necessidades das escolas rurais, dos professores e dos discentes, sobressaiu a ideia de uma escola que falta de tudo, uma escola rural destinada à classe trabalhadora, mas diferente daquela do meio urbano, repleta de precariedades.

Nos documentos analisados, constatamos que a concepção de infância que mais circula nas escolas rurais se aproxima da ideia daquilo que ela deverá vir a ser. Em em nenhum momento, a proposição de valorar o que de fato a criança sabe foi externado. Os relatos de professores colaboradores foram categóricos e demonstraram a importância da inserção da criança no mundo adulto.

A legislação analisada apresentou dois aspectos a saber: por um lado, a perspectiva de consolidação da educação na condição de direito social, um dos desdobramentos das políticas públicas; por outro lado, o poder público se eximiu de suas responsabilidades ao aprovar o projeto de ensino por meio da mediação tecnológica em áreas rurais, proposição desconexa às realidades de alunos e professores. 
Crianças e jovens, estudantes de escolas rurais, são participantes de um modelo de escola pouco adequado aos cotidianos das localidades rurais.

Atirado para a margem do sistema, o ensino rural de crianças e jovens coloca importante desafios às políticas educativas, muitas vezes inadequadas, generalistas e destinadas única e exclusivamente ao cumprimento da legislação. O que é mais característico diante dos documentos analisados é a distância entre ações das administrações públicas - políticas públicas e as realidades das escolas rurais.

O lugar ocupado pela educação pública destinada às crianças, jovens e adultos moradores do meio rural, no município de Porto Velho, foi e é secundário para as agências públicas, que, por seu turno, se ocupam das políticas sociais concernentes ao município e ao estado de Rondônia.

\section{REFERÊNCIAS}

ARIÈS, P. História social da criança e da família. 2 ed. Rio de Janeiro: LTC, 2006.

ARÓSTEGUI, J. A pesquisa histórica: teoria e método. Bauru: Edusc, 2006.

BARROS, J. A.; MORENO AFONSO, J. A. M. Instrução pública primária em Minas Gerais: do ensino rural ao distrital em fins do século XIX e início do XX (1899-1911). In: VECHIA, A.; FERREIRA, A. G. (org.). A crianças e a escolarização: igualdade no espaço latino-americano nos séculos XIX e XX. Curitiba: UTP, 2016.

BARROS, J. A. Organização do ensino rural em Minas Gerais, suas muitas faces em fins do XIX e início do XX (1899 - 1911). 349 f. (Doutorado em Educação) Faculdade de Educação, Universidade Federal de Uberlândia (UFU), Uberlândia, 2013.

BARROS, J. A. Escolas públicas primárias rurais em Minas Gerais: condições materiais e materiais pedagógicos em fins do século XIX e início do XX. In: LIMA, S. C. F. de; MUSIAL, G. B. da S. (org.). Histórias e memórias da escolarização das populações rurais: sujeitos, instituições, práticas, fontes e conflitos. São Paulo: Pacto, 2016.

BEHRING, E. R.; BOSCHETTI, I. Política social: fundamentos e história. 9 ed. São Paulo: Cortez, 2011. 
BENJAMIN, W. Magia e técnica, arte e política. 7. ed. São Paulo: Brasiliense, 1994.

BOF, A. M. (org.). A educação no Brasil rural. Brasília: Inep, 2006.

BOGDAN, R.; BIKLEN, S. Investigação qualitativa em educação: uma introdução à teoria e aos métodos. Porto: Porto, 1994.

BRASIL. Lei de Diretrizes e Bases da Educação Nacional: Lei no 9.394, de 20 de dezembro de 1996, que estabelece as diretrizes e bases da educação nacional. - 5 ed. - Brasília: Câmara dos Deputados, Coordenação Edições Câmara, 2010.

BRASIL. Ministério da Educação e Cultura. Resolução n 1, de 03 de abril de 2002 - Diretrizes Operacionais para a Educação Básica nas Escolas do Campo, Brasilia, 2002.

BURKE, P. Testemunha ocular. São Paulo: Edusc, 2004.

CARVALHO, M. C. A. de; DAMASCENO, E. A.; MOURA, M. do S. L. Navegando em águas turvas no campo da política e da formação de professores. Revista Exitus, [s.l.], v. 9, n. 3, p. 169-196, 1 jul. 2019. Universidade Federal do Oeste do Para. http://dx.doi.org/10.24065/2237-9460.2019v9n3id940. Acesso em: 08 de dezembro de 2019.

CALAZANS, M. J. C. Para compreender a educação do Estado no meio rural. In. THERRIEN, J.; DAMASCENO, M. N. (coord.). Educação e escola no campo. Campinas: Papirus, 1993. p. 15-40.

DUBY, G. A história continua. Rio de Janeiro: Jorge Zahar, 1993.

FALEIROS, V. de P. O que é política social. São Paulo: Brasiliense, 2006.

GIBBS, G. Análise de dados qualitativos. Porto Alegre: Artemed, 2009.

GINZBURG, C. Mitos, emblemas e sinais. 2 ed. São Paulo: Cia das Letras, 2002.

JULIA, D. A cultura escolar como objeto histórico. Revista Brasileira de História da Educação. Campinas, nº 1, p. 9-43, jan./jun.,2001.

LAUWE, M-J. C. Um outro mundo: a infância. São Paulo: EDUSP, 1991. 
LE GOFF, J. História e memória. 5ed. Campinas: UNICAMP, 2003.

LINHARES, M. Y. História Agrária. In: FLAMARION, C. C.; VAINFAS, R. (org.).

Domínios da história. Rio de Janeiro: Campus, 1997. p. 165-184.

MACHADO, M. N. da M. Entrevista de pesquisa: a interação

pesquisador/entrevistado. Belo Horizonte: C / Arte, 2002.

MATIAS, J. C.; BARROS, J. A. As políticas sociais nos planos de governo dos presidenciáveis 2018 no Brasil e a mídia. Revista de Políticas Públicas, [s.I.], v. 23, n. 1, p.339-355, 25 jul. 2019. Universidade Federal do Maranhao. http://dx.doi.org/10.18764/2178-2865.v23n1p339-355. Acesso em: 08 de novembro de 2019.

MATIAS, J. C.; NUNES, M. J. de O.; SILVA, A. L. da; BARROS, J. A. Perspectivas metodológicas e os bordados na pesquisa qualitativa em educação. EDUCA Revista Multidisciplinar em Educação, Porto Velho, v. 6, n. 13, p.128-145, 30 mar. 2019. Educa - Revista Multidisciplinar em Educação.

http://dx.doi.org/10.26568/2359-2087.2019.3721. Acesso em: 10 de dezembro de 2019.

MAXQDA. Software de análise de dados qualiquantitativos. Disponível em: http://www.software.com.br/p/maxqda?gclid=CjwKCAjwyOreBRAYEiwAR2mSku nUy 1111 ADEtbNj1dxIESgbC_WvWwe88eDS-5-

Zh5ZVQwP1 Jey31BoCmtoQAvD_BwE. Acesso em: 01 agosto de 2019.

MOREIRA, C. O. F. Anísio Teixeira e a ideia de progresso. In. FRANCO, C.; KRAMER, S. (orgs.). Pesquisa e educação: história, escola e formação de professores. Rio de Janeiro: Ravil, 1997. p. 26-37.

MOURA, E. B. B. de. Por que as crianças? In: CARVALHO, C. H. et al. A infância na modernidade: entre a educação e o trabalho. Uberlândia: EDUFU, 2007.

NASCIMENTO, M. B. de M.; MARQUES, T. G.; TRINDADE, D. R. da. Jovens do campo no ensino superior. Revista Exitus, [s.l.], v. 10, p. 1-30, 2 abr. 2020. Universidade Federal do Oeste do Para. http://dx.doi.org/10.24065/22379460.2020v10n0id1259. Acesso em: 10 de abril de 2020.

OLARITEA, B. F. O que torna "infantil" uma pesquisa? In: PEREIRA; R. M. R.; SANTOS, N. de O.; LOPES, A. E. R. de C. (org.). Infância, juventude e educação: práticas e pesquisa em diálogo. Rio de Janeiro: NAU, 2015. 
PINTO, S. A infância com construção social. In: PINTO, M.; SARMENTO, M. J. As crianças: contextos e identidades. Braga: UMinho, 1997.

RICOEUR, P. A memória, a história, o esquecimento. Campinas: UNICAMP, 2007.

RONDÔNIA. Lei n 3.346, de 4 de julho de 2016. Projeto Ensino Médio com Mediação Tecnológica no Âmbito da Secretaria de Estado da Educação e dá outras providencias. Assembleia Legislativa de Rondônia, 2016.

SAVIANI, D. Breves considerações sobre fontes para a história da educação. In: LOMBARDI, J. C.; NASCIMENTO, M. I. M. (org.). Fontes, história e historiografia da educação. Campinas: Autores Associados, 2004.

SECCHI, L. Políticas públicas: conceitos, esquemas de análise, casos práticos. 2. ed. São Paulo: Cengage Learning, 2013.

Colaboradora 1. Porto Velho, 20 de setembro 2018. Entrevista concedida aos autores.

Colaboradora 2. Porto Velho, 20 de setembro 2018. Entrevista concedida aos autores.

Colaborador 3. Porto Velho, 11 de março 2019. Entrevista concedida aos autores.

Colaborador 4. Porto Velho, 11 de março 2019. Entrevista concedida aos autores.

Recebido em: 11 de abril de 2020 Aprovado em: 08 de maio de 2020

Publicado em: 22 de julho de 2020

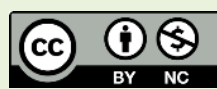

